\title{
Efeito da Aplicação do Poliestireno Sulfonado (PSSNa) como Aditivo em Argamassas e Concretos de Cimento Portland CPV32
}

\author{
Betina Royer, Rosana M. N. Assunção, Guimes Rodrigues Fo \\ Instituto de Química, UFU \\ Leila A. C. Motta \\ Faculdade de Engenharia Civil, UFU
}

\begin{abstract}
Resumo: Neste trabalho foi investigado o uso do Poliestireno sulfonado (PSSNa), produzido a partir de copos plásticos descartáveis de Poliestireno (PS), como aditivo em argamassas e concretos de cimento Portland CPV32. A avaliação do PSSNa como aditivo foi baseada em ensaios de fluidez e resistência mecânica à compressão de corpos de prova. Foi observado, em argamassas com relação água/cimento $(\mathrm{a} / \mathrm{c})$ de 0,48 , um aumento na fluidez com o aumento das porcentagens de PSSNa $(0,25$ a 1,00\%). A adsorção do PSSNa sobre as partículas de cimento melhora a dispersão dos componentes da argamassa, aumentando a resistência mecânica à compressão dos corpos de prova após a cura. A aplicação do PSSNa em concreto apresentou o mesmo efeito. O abatimento do concreto sem PSSNa foi de $50 \mathrm{~mm}$, atingindo cerca de $200 \mathrm{~mm}$ com o uso do polieletrólito. Devido à elevada plasticização observada é possível empregar o PSSNa como aditivo redutor de água. Foi produzido um concreto com o mesmo abatimento da referência sem aditivo reduzindo-se a quantidade de água em 20,8\%. O ganho de resistência mecânica à compressão obtido foi de 21,5 e 26,3 \%, respectivamente aos 7 e 28 dias de cura. Estes resultados mostraram que soluções de PSSNa podem atuar eficientemente como aditivo superplastificante ou redutor de água em argamassas e concretos.
\end{abstract}

Palavras-chave: Poliestireno sulfonato de sódio (PSSNa), aditivo, argamassas, concreto.

\section{Effect of PSSNa as admixture in Mortars and Concrete of Cement Portand CPV32}

Abstract: In this work an investigation was made of the effects from adding PSSNa, obtained from disposable polystyrene (PS) cups, as admixture agent in mortars and concrete with varying ratios from 0.25 to $1.00 \%$. The evaluation of PSSNa as additive was based on results of fluidity and mechanical strength to compression. In mortars with water/cement ratio of 0.48 , an increase in flow was observed when the dosage of PSSNa varied from 0.25 to $1.00 \%$. The dispersion of mortar components was improved due to the adsorption of PSSNa on cement particles, which increased the mechanical strength of mortars. Similar results were obtained with the application of PSSNa to concrete. The slump of the concrete taken as reference was $50 \mathrm{~mm}$, while for the concrete with PSSNa it reached about $200 \mathrm{~mm}$. Because of its plasticization of concrete, PSSNa can be used as additive to reduce the amount of water required. For instance, a concrete with the same slump of the reference concrete was produced using PSSNa and a reduction of $20.8 \%$ in the volume of water. The increase in mechanical strength was 21.5 and $26.3 \%$, respectively, at 7 and 28 days of curing. These results showed that PSSNa solutions can act as superplasticizer or as admixture to reduce the amount water in mortars and concretes.

Keywords: PSSNa, admixture, mortar, concrete.

\section{Introdução}

Reciclar hoje em dia significa transformar uma fonte de despesa em uma fonte para obtenção de novos materiais. A reciclagem é uma alternativa para tentar retirar do meio ambiente, os rejeitos e resíduos que diariamente são produzidos pela nossa sociedade. No Brasil, o interesse na reciclagem de materiais poliméricos vem crescendo significativamente. Neste sentido, a busca por rotas viáveis do ponto de vista econômico, vem sendo estudada para a aplicação destes novos materiais em diversos segmentos da sociedade ${ }^{[1]}$.

O poliestireno é um dos polímeros de maior participação na produção de materiais descartáveis tais como copos plásticos, bandejas de alimentos, sacolas plásticas, etc. Um caminho alternativo para reaproveitamento do poliestireno descartado consiste em sua transformação química para produção de um novo material ${ }^{[2]}$. O poliestireno é um polímero que pode ser facilmente sulfonado, devido

Autor para correspondência: Guimes Rodrigues Fo, Instituto de Química, Universidade Federal de Uberlândia, Av. João Naves de Ávila 2160, CEP: 38400 902, Uberlândia, MG. E-mail: guimes@ufu.br. 
à sua capacidade de sofrer substituições eletrofílicas nos anéis benzênicos ligados à cadeia polimérica ${ }^{[3,4]}$.

O poliestireno modificado quimicamente pode ser empregado como floculante em tratamento de águas industriais ${ }^{[2]}$ e dispersante para cimento na preparação de pastas de cimento, argamassas e concretos ${ }^{[5-7]}$.

A aplicação na construção civil de materiais poliméricos é bastante difundida na atualidade, sendo um caminho viável de reaproveitar materiais reciclados. A construção civil utiliza o concreto como material estrutural de maior aplicação devido a sua grande resistência a água e sua fácil moldagem em formas complexas ${ }^{[8]}$. No entanto, a associação de vários materiais ao concreto tem se mostrado um caminho eficaz na melhora das propriedades mecânicas tais como resistência à compressão e a tração, durabilidade e propriedades químicas ${ }^{[9,10]}$. Neste sentido, a utilização de aditivos em materiais de construção é anti-

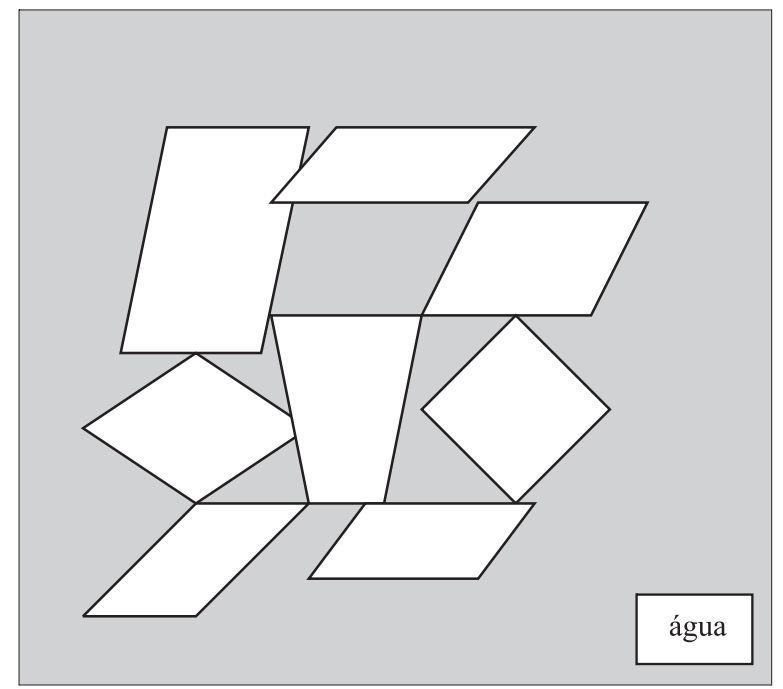

(a) Adição de água ao cimento sem a presença do aditivo: ocorre a formação de flocos

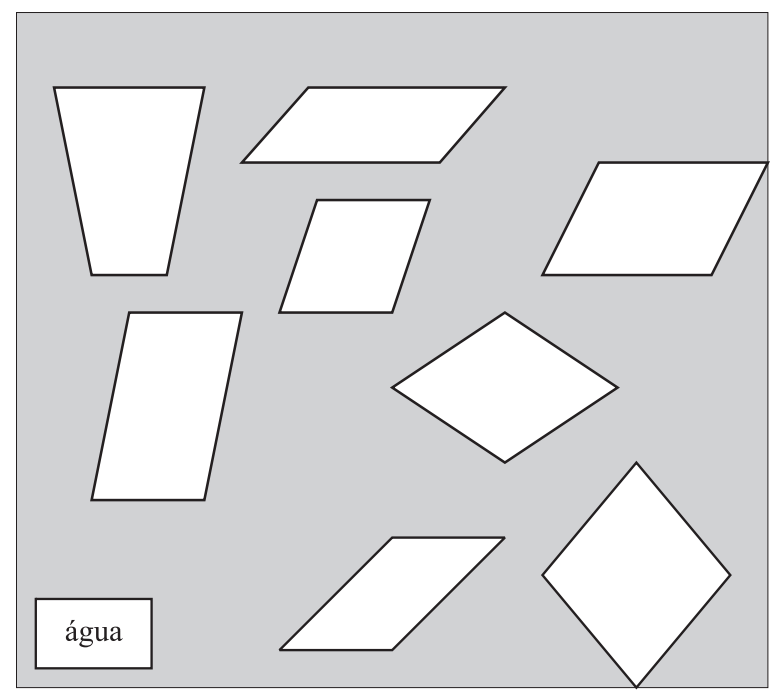

(b) Adição de água ao cimento com a presença do aditivo: ocorre a melhora na dispersão das partículas de cimento

Figura 1. Representação esquemática do mecanismo de dispersão ${ }^{[8]}$. ga. Inicialmente, substâncias normalmente constituídas por polímeros (como por exemplo, os derivados sulfonados naftaleno-formaldeído) eram disponíveis comercialmente, contudo sua utilização era pequena pois, como a resistência mecânica à compressão solicitada para concretos e argamassas era muito baixa, podia-se variar a relação água/cimento $(\mathrm{a} / \mathrm{c})$ para atingir a trabalhabilidade desejada ${ }^{[11]}$. No entanto, este quadro vem sendo alterado gradativamente ao longo dos anos com o aumento da exigência mecânica (resistências à tração e a compressão) das estruturas produzidas. O primeiro aditivo redutor de água utilizado pela indústria da construção civil foi um polímero dispersante a base de lignina (lignossulfonatos), um subproduto de baixo custo da indústria do pape ${ }^{[11]}$. Com o uso de polímeros sintéticos como os derivados sulfonados do naftaleno-formaldeído e da melanina-formaldeído abriram-se perspectivas para aplicação de novos materiais.

Atualmente novos polímeros estão sendo investigados para esta função tais como suspensões à base de látex (borracha natural e sintética), emulsão à base de poliacrilatos, propionato de polivinila, acetato de polivinila e polímeros solúveis em água tais como a metil celulose, o álcool polivinílico, poliacrilamidas e policarboxilatos ${ }^{[9,12]}$. Devido a crescente popularização destes novos materiais, vem crescendo o interesse em utilizar materiais poliméricos descartados como fontes de baixo custo cujo processo de modificação química seja de fácil execução ${ }^{[2]}$. $\mathrm{Na}$ sulfonação do poliestireno descartado, produz-se um polieletrólito que, devido à presença dos grupos sulfônicos pode ser capaz de atuar como um aditivo. O mecanismo de ação de alguns aditivos é baseado em fenômenos de adsorção do polieletrólito pelas partículas de cimento. Neste processo, o polieletrólito com grupos sulfônicos ligados à cadeia se adsorve às partículas de cimento conferindo a estas, carga líquida negativa. Este efeito provoca repulsão entre as partículas de cimento favorecendo sua dispersão em água e evitando a floculação do cimento ${ }^{[8]}$. Este mecanismo encontra-se apresentado na Figura 1.

O mecanismo proposto para atuação de alguns tipos de aditivos justifica a utilização do poliestireno sulfonado como aditivo, neste sentido, neste trabalho avaliou-se uma solução aquosa do poliestireno sulfonado sódico em argamassa e concretos quanto ao aumento da trabalhabilidade e da resistência mecânica à compressão.

\section{Experimental}

\section{Preparação do Poliestireno Sulfonado}

Para a sulfonação do poliestireno (PS) obtido a partir de copos plásticos da marca ZANATA pós-consumo preparou-se uma solução do polímero em diclorometano. Nesta solução adicionou-se como agente sulfonante anidrido acético e acido sulfúri$\operatorname{co}^{[13]}$. Após aproximadamente 24 horas de reação à temperatura ambiente, o produto apresentava um aspecto gelatinoso, de coloração marrom esverdeado. O produto final foi solubilizado em água e tratado com uma solução de $\mathrm{NaOH}$ até atingir pH igual a 9. A concentração final da solução foi de $17 \%(\mathrm{~m} / \mathrm{m})$.

A solução preparada de PSSNa foi aplicada como aditivo para argamassas e concretos na construção civil. 
Tabela 1- Proporção dos componentes da argamassa de cimento CPV32.

\begin{tabular}{cc}
\hline Componentes & Massa / g \\
\hline Cimento Portland CPV32 & 624 \\
Areia fina & 1872 \\
Água & 300 \\
\hline
\end{tabular}

\section{Preparação dos corpos de prova de argamassas e concretos}

Foram retiradas alíquotas da solução preparada para produção de argamassas com proporções de aditivo em relação à massa de cimento que variam de 0,25 e $1,0 \%$. As amostras foram preparadas a partir da mistura manual dos componentes, cimento, areia, água e aditivo conforme informações da Tabela 1.

A partir das quantidades descritas na Tabela 1, foram preparados 8 corpos de prova cilíndricos, com dimensões aproximadas de $10,0 \mathrm{~cm}$ de comprimento e $5,0 \mathrm{~cm}$ de diâmetro. Para a preparação das amostras com aditivo, mantiveram-se as mesmas proporções acima, adicionando-se apenas a massa de aditivo. A massa de água usada no preparo da solução é descontada, pois apenas adiciona-se água suficiente para manter a relação a/c de 0,48 .

A consistência das argamassas foi medida usando-se uma mesa para determinação do índice de consistência, de acordo com a norma técnica NBR 7215. A argamassa após a preparação foi colocada em uma forma troncocônica sobre uma mesa plana com uma manivela. Após o preenchimento, a forma foi retirada e em seguida a manivela da mesa foi movimentada 30 vezes por $30 \mathrm{~s}$. O diâmetro da argamassa após o ensaio foi medido. A plastificação $(\omega \%)$ foi obtida a partir do resultados experimentais e da equação (1) ${ }^{[14]}$ :

$$
\omega \%=100 .\left(D_{m}-D_{o}\right) / D_{o}
$$

onde: $\mathrm{D}_{\mathrm{o}}$ éo diâmetro da base $(125 \mathrm{~mm})$ da forma troncocônica preenchida com a argamassa e $\mathrm{D}_{\mathrm{m}}$ é o diâmetro da argamassa após a realização do ensaio.

Os ensaios de compressão foram realizados em uma máquina universal de ensaio mecânico Losenhausen. Os testes foram realizados após 7 dias de cura.

As misturas de concreto foram preparadas empregando-se a dosagem de aditivo de $0,28 \%$ em relação à massa de cimento. Os componentes do concreto foram misturados por 7 minutos em betoneira. $\mathrm{O}$ traço (proporção entre os componentes do concreto, cimento: areia: brita: água) foi preparado de modo a pro-

Tabela 2. Componentes para preparação do concreto de Portland CPV32 $\left(355 \mathrm{Kg} / \mathrm{m}^{3}\right)$, traço 1:1,92:3,31:0,53 (cimento: areia: brita: água).

\begin{tabular}{cc}
\hline Componentes & \% dos componentes \\
\hline cimento Portland & 14,80 \\
areia média (módulo de finura) & 28,43 \\
brita (tamanho médio de $19 \mathrm{~mm})$ & 48,93 \\
água & 7,84 \\
\hline
\end{tabular}
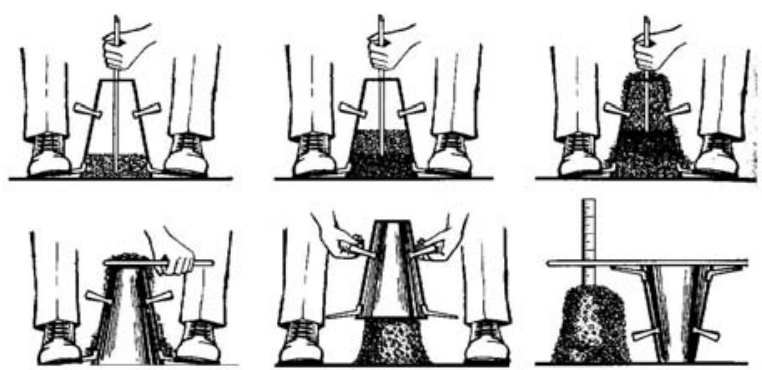

Figura 2. Ensaio para determinação da consistência do concreto através do abatimento do tronco de cone.

duzir um concreto com um consumo de cimento de $355 \mathrm{~kg} / \mathrm{m}^{3}$, conforme o apresentado na Tabela 2. A solução de PSSNa foi adicionada ao concreto durante a mistura.

$\mathrm{O}$ abatimento do concreto foi medido por meio da técnica do abatimento do tronco de cone (norma técnica Brasileira NBR 7223) após mistura do concreto conforme o apresentado na Figura 2.

Após o ensaio de abatimento do tronco de cone, foram moldados 12 corpos-de-prova de dimensões aproximadas de $20 \mathrm{~cm}$ de comprimento e $15 \mathrm{~cm}$ de diâmetro, para o concreto de referência sem aditivo e o mesmo número para o concreto com aditivo. A resistência à compressão do concreto foi determinada através da média dos resultados do ensaio de 4 corpos-de-prova de cada um dos concretos aos 7 e 28 dias de cura. A escolha destas idades do concreto foi feita em relação aos processos de hidratação do concreto e conseqüentemente o ganho de resistência à compressão durante estes tempos.

Os testes de resistência à compressão foram realizados em uma máquina de ensaio mecânico de compressão Losenhausen, onde 4 corpos-de-prova de referência sem aditivo e 4 corpos-deprova com aditivo foram rompidos em cada uma das idades.

\section{Resultados e Discussão}

\section{Aplicação das soluções de PSSNa como aditivo para argamassas}

O estudo da fluidificação das argamassas foi realizado utilizando-se uma relação a/c de 0,48 . Esta relação a/c foi escolhida pois é a empregada para a preparação de argamassas padrão para a determinação da resistência mecânica à compressão de cimento Portland, de acordo com a norma técnica

Tabela 3. Resultado do ensaio do índice de consistência e resistência à compressão para argamassas $(\mathrm{a} / \mathrm{c}=0,48)$.

\begin{tabular}{ccc}
\hline Argamassas & $\begin{array}{c}\text { Consistência } \\
(\mathbf{m m})\end{array}$ & $\begin{array}{c}\text { Resistência mecânica à } \\
\text { compressão } \\
(\mathbf{M P a})-7 \text { dias }\end{array}$ \\
\hline referência & 133,3 & 17,65 \\
$0,25 \%$ & 139,4 & 18,62 \\
$0,50 \%$ & 143,9 & 19,60 \\
$0,75 \%$ & 147,2 & 20,50 \\
$1,00 \%$ & 157,3 & 20,84 \\
\hline
\end{tabular}




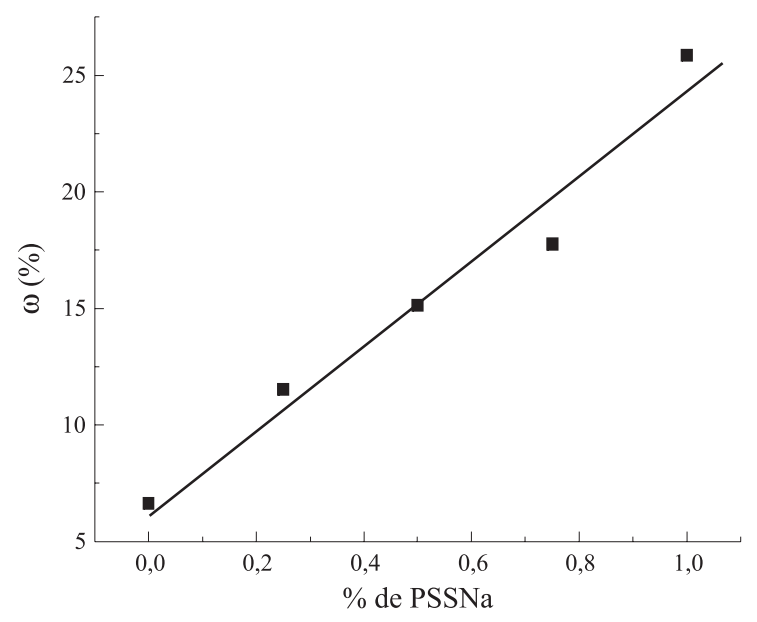

Figura 3. Efeito de plastificação em função da porcentagem de PSSNa utilizada nos ensaios de consistência.

NBR 7215. Neste estudo avaliou-se a trabalhabilidade (fluidificação) e a resistência à compressão das argamassas sem redução da relação a/c das amostras com aditivo em comparação com uma referência sem aditivo. O índice de consistência para argamassas encontra-se na Tabela 3.

A partir dos resultados apresentados na Tabela 3, foi observado um aumento no índice de consistência das argamassas com o aumento da porcentagem de PSSNa adicionado, este fato é observado para aditivos comerciais ${ }^{[15]}$ e caracteriza a melhora da trabalhabilidade e da fluidez da argamassa. Fisicamente nestas amostras observa-se um sistema mais homogêneo. A melhora na trabalhabilidade das argamassas ocorre devido a um efeito de plastificação produzido com o uso do PSSNa. Este efeito pode ser avaliado por meio da equação 1, apresentada anteriormente, e pode ser observado na figura 3.

O efeito de plastificação ocorre, possivelmente, devido ao fato do PSSNa agir como um tensoativo melhorando o processo de dispersão das partículas de cimento ${ }^{[8,15]}$. A intensificação do efeito de plasticização com o aumento na dosagem da solução de PSSNa pode ser explicada considerando que pode ocorrer um aumento na adsorção deste pelas partículas de cimento o que resulta em uma melhora na fluidificação da argamassa. Dentro da faixa de PSSNa utilizada, constatou-se que este polieletrólito pode ser considerado como um aditivo plastificante uma vez que apresenta efeitos de plastificação das argamassas testadas e os valores de dosagem entre 0,2 e $2,0 \%$ são os encontrados na literatura, para materiais desta natureza ${ }^{[15]}$. É importante salientar que, quanto maior a dosagem de PSSNa maior será o efeito de plastificação como apresentado na Figura 3, no entanto a melhor dosagem a ser aplicada depende da análise conjunta de vários efeitos como os de plastificação, redução de água e ganho de resistência à compressão, uma vez que elevadas quantidades de aditivos podem levar misturas de argamassas e concretos à segregação $^{[8,16]}$.

$\mathrm{O}$ uso de aditivos como agentes plastificantes pode levar a um ligeiro aumento na resistência mecânica à compressão, como pode ser observado na Tabela 3, quando se aplica uma solução de PSSNa. A melhora no processo de dispersão das partículas de cimento favorece a formação dos compostos de hidratação do cimento responsáveis pelo ganho de resistência. Em baixa dosagem do aditivo o ganho de resistência à compressão é pouco significativo, cerca de $5,50 \%$. Para amostras com maior dosagem $(0,75$ e $1,00 \%)$ se atinge um ganho de resistência de cerca de $18,1 \%$, isto ocorre devido a maior concentração do PSSNa no processo de adsorção. Embora, o aumento significativo na resistência mecânica à compressão ocorra para maiores dosagens do PSSNa, o emprego de aditivos comerciais com a função de aumentar a resistência mecânica é realizado com o intuito de diminuir a água de amassamento do concreto. Este fator tem um efeito significativo na diminuição do número de poros e no aumento da resistência mecânica à compressão. Deste modo, o aumento da resistência a compressão com o aumento da dosagem do PSSNa empregado mostra que o polieletrólito produzido plasticiza eficientemente a argamassa a ponto de interferir de forma benéfica na formação dos compostos de hidratação do cimento.

\section{Aplicação do PSSNa em concretos de cimento CPV32}

Para avaliar o desempenho do PSSNa como aditivo em concreto utilizou-se uma dosagem de $0,28 \%$ de uma solução aquosa de PSSNa em relação à massa de cimento. A porcentagem escolhida para aplicação no concreto foi baseada em 3 aspectos essenciais: i) o emprego de elevadas porcentagens de aditivo pode elevar a segregação do concreto ${ }^{[8,13]}$, testes iniciais com uma faixa de 0,20 a $1,50 \%$ mostraram um bom desempenho do PSSNa, no entanto para elevada porcentagem, acima de $1,50 \%$, o aumento significativo do abatimento do concreto é perdido rapidamente inviabilizando o uso deste após longos tempos de mistura e de transporte, ii) do ponto de vista comercial o emprego de baixas porcentagens é interessante uma vez que o aditivo é o componente mais caro da mistura, no entanto, o efeito do PSSNa pode ser considerável em baixas porcentagens, como se observou neste trabalho nos testes para argamassas, onde ocorre plastificação da argamassa mesmo em baixas porcentagens e iii) existem outros fatores a se considerar durante a preparação das misturas, embora, a argamassa possa fornecer informações quanto a interação entre o cimento, a areia e o aditivo, a introdução do agregado graúdo no concreto muda as interações entre as fases do concreto e neste caso, a atuação do aditivo, sendo portanto, interessante o estudo de dosagens baixas a moderadas. Neste trabalho, a escolha de uma baixa dosagem evita a preocupação com a segregação da mistura.

Os resultados obtidos na aplicação do PSSNa em argamassa mostraram a possibilidade de se aplicar o polieletrólito em concreto, devido ao aumento de fluidez observado nos ensaios. Deste modo, o aumento da fluidez pode ser empregado tanto para melhorar a trabalhabilidade do concreto, mantendo a resistência mecânica original sem aditivo, como para reduzir o conteúdo de água do concreto. Este procedimento permite obter concretos com resistência à compressão mais elevada e abatimento igual ou superior à referência sem aditivo. Os resultados obtidos da aplicação de uma solução aquosa $0,28 \%$ de PSSNa ao concreto estão resumidos na Tabela 4. 
Tabela 4. Avaliacão dos testes de abatimento e resistência para concretos de cimento CPV32.

\begin{tabular}{lcccc}
\hline Concretos & $\begin{array}{c}\text { Relação } \\
\mathbf{a} / \mathbf{c}\end{array}$ & $\begin{array}{c}\text { Abatimento } \\
(\mathbf{m m})\end{array}$ & \multicolumn{2}{c}{$\begin{array}{c}\text { Resistência à } \\
\text { Compressão (MPa) }\end{array}$} \\
\cline { 5 - 6 } & & & $\mathbf{7}$ dias & 28 dias \\
\hline referência & 0,53 & 51 & 27,99 & 32,50 \\
$0,28 \%$ de & 0,53 & 200 & 29,37 & 37,26 \\
PSSNa (A) & & & & \\
$0,28 \%$ de & 0,42 & 53 & 34,02 & 41,03 \\
PSSNa (B) & & & & \\
\hline
\end{tabular}

O ensaio (A) foi realizado com o intuito de verificar o efeito de fluidificação do concreto mantendo-se a relação a/c igual à referência sem aditivo. Observa-se um aumento significativo na fluidificação do concreto e, conseqüentemente, uma melhora no adensamento deste, que pode ser observada durante a realização do ensaio do abatimento do tronco de cone. Um efeito desta natureza é desejável quando o concreto deve ser lançado por bombeamento. Neste procedimento observou-se também que o concreto obtido desta forma tem resistência mecânica ligeiramente superior ao concreto de referência $(6,4 \%$ e $14,6 \%$ aos 7 e 28 dias de cura respectivamente). No ensaio (B) reduziu-se a água usada para amassamento do concreto de forma a se obter um concreto com um abatimento próximo ao da referência. Com o uso do PSSNa foi possível obter uma redução de água de $20,8 \%$. Neste caso, a resistência mecânica à compressão teve um aumento significativo de $21,54 \%$ e de $26,25 \%$ aos 7 e 28 dias de cura, respectivamente, em relação à resistência mecânica à compressão dos concretos de referência. O resultado observado mostra que com o uso de pequenas proporções do PSSNa é possível obter abatimentos elevados (de $50 \mathrm{~mm}$ para o concreto seco, para $200 \mathrm{~mm}$ para o concreto com $0,28 \%$ de PSSNa) em ensaios para aumento da trabalhabilidade e em ensaios para o aumento da resistência mecânica à compressão com o uso deste material se obtém uma redução de água de 20,8\%. Estes resultados, com relação ao abatimento e a redução de água, permitem classificar o PSSNa como um aditivo superplastificante ou redutor de água de alto desempenho.

\section{Conclusões}

O PSSNa produzido a partir da sulfonação de copos plásticos descartáveis de PS foi aplicado em argamassas onde se mostrou eficiente, uma vez que se observou um aumento na plastificação das argamassas. A presença deste material é benéfica em relação à resistência à compressão uma vez que, para todas as dosagens ocorre um ganho de resistência explicado pela melhora nos processos de dispersão e homogeneização do cimento. $\mathrm{O}$ efeito positivo da aplicação deste material pode ser comprovado em sua utilização no concreto. Observou-se elevada fluidificação em ensaios para aumento de trabalhabilidade com a aplicação de uma dosagem baixa de PSSNa cerca de 0,28\%. Com esta dosagem foi possível obter uma redução de água de $20,8 \%$ com um aumento na resistência mecânica à compressão de $26,3 \%$ aos 28 dias de cura do concreto, permitindo classificar o PSSNa como aditivo superplastificante.

\section{Agradecimentos}

Os autores agradecem a FAPEMIG, convênio 1803/98 e CEX 1658/03. Assunção agradece à FAPEMIG (bolsa de recém-doutor projeto: CEX 00009/01) pelo apoio financeiro. Royer agradece ao PIBIC-UFU pela bolsa de Iniciação Científica projeto $\mathrm{n}^{\circ} \mathrm{A}-017 / 2003$.

\section{Referências Bibliográficas}

1. Muñoz-Escalona, A. - In: anais $2^{\underline{0}}$ Simpósio Ibero-Americano de Polímeros (SIAP), 4ํ Simpósio Latino-Americano de Polímeros (SLAP) e $6^{0}$ Colóquio Internacional de Macromoléculas, Gramado, RS, (1994).

2. Inagaki, Y.; Kuromiya, M.; Noguchi, T. \& Watanabe, H. Langmuir, 15, p.4171 (1999).

3. Holboke, A. E. \& Pinnell, R. P. J. - Chem. Education, 66(7), p.613, (1989).

4. Kucera, F. \& Jancar, J. - Polymer Engineering and Science, 38(5), p.783 (1998).

5. El-Hosiny, F. I. \& Gad, E. A. - Journal of Applied Polymer Science, 56(2), p.153 (1995).

6. Assunção, R. M .N.; Royer, B.; Oliveira, J. S.; Rodrigues Filho, G. \& Motta, L. A. C. - in: Anais do $6^{\circ}$ Congresso Brasileiro de Polímeros / IX International Macromolecular Coloquium Gramado, p.1857 (2001).

7. Royer, B.; Assunção, R. M. N.; Rodrigues Fº , G. \& Motta, L. A C. - J. Appl. Polymer Science, no prelo

8. Metha, P. \& Monteiro, J. M. P. - Concreto - Estrutura, Propriedades e Materiais, Pini, São Paulo (1994)

9. Ohama, Y. - Advn Cem Bas Mat, 5, p.31 (1997).

10. Fowler, D. W. - Cement and Concrete Research, 21, p.449 (1999).

11. Neville, A. M. - Propriedades do Concreto, 2ed, Pini, São Paulo (1997).

12. Yamada, K.; Takahashi, T.; Hanehara, S. \& Matsuhisa, M. Cement and Concrete Research, 30, p.197 (2000).

13. Baigl, D.; Seery, T. A. P. \& Williams, C. E. - Macromolecules, 35 , p.2318 (2002).

14. Kamour, A., Jelidi, A. \& Chaabouni, M. - Cement and Concrete Research, 1-9, p.2279 (2003).

15. Collepardi, M. - Cement and Concrete Composites, 20, p.103 (1998).

16. IPT - Instituto de Pesquisas Tecnológicas do Estado de São Paulo - Tecnologia de Aditivos, São Paulo, (1983).

Enviado: 14/06/04

Reenviado: 09/12/04

Aprovado: 27/12/04 